\title{
Synthesis, Optical, Chemical and Thermal Characterizations of PMMA-PS/CeO 2 Nanoparticles Thin Film
}

\author{
Areen A. Bani-Salameh ${ }^{1}$, A. A. Ahmad ${ }^{1}\left(\mathbb{D}\right.$, A. M. Alsaad ${ }^{1, *(\mathbb{D})}$, I. A. Qattan ${ }^{2}$ and Ihsan A. Aljarrah ${ }^{1}$ \\ 1 Department of Physical Sciences, Jordan University of Science \& Technology, P.O. Box 3030, \\ Irbid 22110, Jordan; areensalameh92@gmail.com (A.A.B.-S.); sema_just@yahoo.com (A.A.A.); \\ ihsanaljarrah@gmail.com (I.A.A.) \\ 2 Department of Physics, Khalifa University of Science and Technology, Abu Dhabi P.O. Box 127788, \\ United Arab Emirates; issam.qattan@ku.ac.ae \\ * Correspondence: alsaad11@just.edu.jo or amalsaad@unomaha.edu; \\ Tel.: +962-791314650 or $+962-7201000$ (ext. 23422)
}

check for updates

Citation: Bani-Salameh, A.A.; Ahmad, A.A.; Alsaad, A.M.; Qattan, I.A.; Aljarrah, I.A. Synthesis, Optical, Chemical and Thermal Characterizations of PMMAPS $/ \mathrm{CeO}_{2}$ Nanoparticles Thin Film. Polymers 2021, 13, 1158. https:// doi.org/10.3390/polym13071158

Academic Editors: Andrzej Rybak and Karolina Gaska

Received: 19 February 2021

Accepted: 25 March 2021

Published: 4 April 2021

Publisher's Note: MDPI stays neutral with regard to jurisdictional claims in published maps and institutional affiliations.

Copyright: (c) 2021 by the authors. Licensee MDPI, Basel, Switzerland. This article is an open access article distributed under the terms and conditions of the Creative Commons Attribution (CC BY) license (https:// creativecommons.org/licenses/by/ $4.0 /)$
Abstract: We report the synthesis of hybrid thin films based on polymethyl methacrylate) (PMMA) and polystyrene (PS) doped with $1 \%, 3 \%, 5 \%$, and $7 \%$ of cerium dioxide nanoparticles $\left(\mathrm{CeO}_{2} \mathrm{NPs}\right)$. The As-prepared thin films of (PMMA-PS) incorporated with $\mathrm{CeO}_{2} \mathrm{NPs}$ are deposited on a glass substrate. The transmittance $\mathrm{T} \%(\lambda)$ and reflectance $\mathrm{R} \%(\lambda)$ of PMMA-PS/ $\mathrm{CeO}_{2}$ NPs thin films are measured at room temperature in the spectral range (250-700) nm. High transmittance of $87 \%$ is observed in the low-energy regions. However, transmittance decreases sharply to a vanishing value in the high-energy region. In addition, as the $\mathrm{CeO}_{2} \mathrm{NPs}$ concentration is increased, a red shift of the absorption edge is clearly observed suggesting a considerable decrease in the band gap energy of PMMA-PS/ $\mathrm{CeO}_{2}$ NPs thin film. The optical constants ( $\mathrm{n}$ and $\mathrm{k}$ ) and related key optical and optoelectronic parameters of PMMA-PS/Ce NPs thin films are reported and interpreted. Furthermore, Tauc and Urbach models are employed to elucidate optical behavior and calculate the band gaps of the as-synthesized nanocomposite thin films. The optical band gap energy of PMMA-PS thin film is found to be $4.03 \mathrm{eV}$. Optical band gap engineering is found to be possible upon introducing $\mathrm{CeO}_{2}$ NPs into PMMA-PS polymeric thin films as demonstrated clearly by the continuous decrease of optical band gap upon increasing $\mathrm{CeO}_{2}$ content. Fourier-transform infrared spectroscopy (FTIR) analysis is conducted to identify the major vibrational modes of the nanocomposite. The peak at $541.42 \mathrm{~cm}^{-1}$ is assigned to $\mathrm{Ce}-\mathrm{O}$ and indicates the incorporation of $\mathrm{CeO}_{2} \mathrm{NPs}$ into the copolymers matrices. There were drastic changes to the width and intensity of the vibrational bands of PMMA-PS upon addition of $\mathrm{CeO}_{2}$ NPs. To examine the chemical and thermal stability, thermogravimetric (TGA) thermograms are measured. We found that (PMMA-PVA) $/ \mathrm{CeO}_{2} \mathrm{NPs}$ nanocomposite thin films are thermally stable below $110{ }^{\circ} \mathrm{C}$. Therefore, they could be key candidate materials for a wide range of scaled multifunctional smart optical and optoelectronic devices.

Keywords: hybrid thin films; optical properties; $\mathrm{CeO}_{2}$ nanoparticles; polystyrene (PS); polymethyl methacrylate (PMMA); chemical properties; thermal properties

\section{Introduction}

Nanocomposites based on blending polymers with inorganic nanoparticles have attracted much attention owing to their projected extraordinary thermal, optical, electrical and antibacterial properties [1-4]. The motivation for using inorganic materials stems from their high thermal stability, good electrical properties and high refractive index $n[5,6]$. However, previous studies indicate several drawbacks and insufficient capability of inorganic nanoparticles to serve a variety of modern device applications [7]. Of these disadvantages, there are the deficiency of elasticity, high cost and their high densities. As a result, several researchers were motivated to search for nanocomposite materials based on blending inorganic nanoparticles with organic materials to improve their properties 
and obtain nanocomposites with better features. Owing to the outstanding properties of organic materials such as good flexibility, lower weight compared to inorganic materials, as well as the easiness of preparation, low processing cost, good influence resistance [8-10], recyclability and being environmentally friendly, they serve as excellent candidates for inorganic-organic nanocomposites [11,12].

High transparency and high refractive index are two essential optical parameters that are highly demanded for the manufacturing of smart multi-functional optoelectronics devices [9]. Careful design of such nanocomposites could yield materials that can be employed in sophisticated sensors [13,14], optical crystals [15], micro-lenses for imaging and medical applications [16,17] and ultra-fast data transmission [10]. Polymers with high refractive indices are key candidate materials for smart-scaled multi-functional materials. For instance, poly(thiophene) exhibits a refractive index of 2.12 at a wavelength of $632 \mathrm{~nm}[16,18-20]$. However, they are difficult to prepare. Despite the high absorption coefficient and apart from the difficulty of preparing, it absorbs light in the visible light region and has high optical dispersion [15]. In light of the above issues, overcoming these limitations and developing organic materials with better properties becomes of utmost importance.

The main challenge is to explore the possibility of preparing polymers thin films with specific properties for specific applications. Polymethyl methacrylate (PMMA) polymer has an excellent optical, electrical, mechanical, and thermal characteristic. The exceptional properties of PMMA such as, high transparency, environmental stability, low cost, easy preparation and shaping at low temperature make it an excellent candidate for fabricating thin films [21-23]. However, its application is limited at higher temperatures owing to its relatively poor thermal stability [24]. To overcome this problem, elaborated technological techniques are applied to improve different characteristics of PMMA polymer [24-26]. Polystyrene (PS) is one of the most common thermoplastic polymers. It is colorless and transparent in the visible region. PS has a good formability, a good rigidity, electric and thermal insulation, easy processing and long-term stability [27-29]. The outstanding properties of polystyrene such as its low cost and high refractive index of 1.59 at a wavelength of $632 \mathrm{~nm}$ make it an excellent choice for several optical applications [8].

Controlling the properties of materials is like sculpturing uniquely on scrolls. The properties of the films can be tuned in several ways, such as changing the film thickness [30-34] or by developing hybrid films of the metal oxide polymer [8,35]. In addition, the properties of the polymers can be improved by introducing nanoparticles into the polymer matrix. This is an approach that opens the door to many applications in various fields. The merging of nanoparticles into the polymer matrix improves their optical, mechanical, thermal and electronic properties [8,36,37]. Due to the simple synthesis and low cost of preparation, the merging of inorganic building blocks in the organic matrix is an effective way to improve the properties while maintaining high transparency [38,39]. Amongst nanoparticles, cerium oxide nanoparticles $\left(\mathrm{CeO}_{2} \mathrm{NPs}\right)$ have attracted much attention for their high stability, surface chemistry, and biocompatibility [40-42]. $\mathrm{CeO}_{2} \mathrm{NPs}$ are transparent in the visible region and have a refractive index of 2.2 at a wavelength of $632 \mathrm{~nm}[8,43]$. Pure $\mathrm{CeO}_{2}$ exhibits a wide indirect optical band gap and energy-wide band gap that operates effectively in the ultraviolet (UV) region and thus it could be an excellent choice for different optical and electronic applications [44,45].

Optics are playing a crucial role in many of our day-to-day applications. The refractive index is one of the most significant parameters in photonics. An increase in the efficiency of the photonic devices, like LEDs, modern solar systems, can be performed by engineering the refractive index mismatch of materials used in the optical devices. The novelty of this work is underlined by refractive index modulation using polymer nanocomposites treated with inorganic fillers. Other related optical parameters of the fabricated optical devices can be tuned accordingly. By careful choice of synthetic methods and manipulating the distinctive physics of the polymeric nanocomposites in such materials, novel-scaled 
functional polymer-inorganic nanocomposites can be designed and manufactured for new and interesting optoelectronic applications.

\section{Experimental Details and Techniques}

Polystyrene (PS) with a molecular weight $104.1 \mathrm{~g} / \mathrm{mol}$, polymethyl methacrylate (PMMA) with a molecular weight $3617 \mathrm{~g} / \mathrm{mol}$, and Ceria NPs with molecular weight $172 \mathrm{~g} / \mathrm{mol}$ were purchased from Sigma Aldrich (St. Louis, MO, USA). Polystyrene (PS) solution was prepared in a conical flask by dissolving $2 \mathrm{~g}$ of PS in $200 \mathrm{~mL}$ of tetrahydrofuran (THF) Sol(A) and then placed on a stirrer for $1 \mathrm{~h}$. Polymethyl methacrylate (PMMA) solution was prepared by dissolving $2 \mathrm{~g}$ of PMMA in $200 \mathrm{~mL}$ THF Sol(B) under continuous stirring for $1 \mathrm{~h}$. Immediately after that, Sol (A) was added to Sol (B) under continuous stirring to synthesize 1:1 co-polymeric matrix. The polymeric mixture is expected to exhibit extraordinary physical, thermal and optical properties. Cerium oxide nanoparticles purchased from (Sigma Aldrich, St. Louis, MO, USA) of size (25-50) nm were added to as-prepared copolymers matrix with different concentration ratios $(1 \%, 3 \%, 5 \%$ and $7 \%$ ). To ensure that $\mathrm{CeO}_{2}$ nanoparticles were incorporated homogenously into the PMMA-PS matrix, the solution was alternatively mixed on a magnetic stirrer and a sonication rod. The substrates were cleaned and rinsed using ethanol and distilled water. The PMMA-PS/CeO nanocomposite thin films were synthesized by dip-coating technique. The two layers were dried at $70{ }^{\circ} \mathrm{C}$ for $30 \mathrm{~min}$ for each layer. The effect of introducing $\mathrm{CeO}_{2}$ nanoparticles on the optical properties was performed using UV-Vis spectrophotometer (U-3900H) (Hitachi, Fukuoka, Japan) with a total internal integrating sphere. Particularly, transmittance T\% $(\lambda)$ and reflectance $\mathrm{R} \%(\lambda)$ of PMMA-PS $/ \mathrm{CeO}_{2} \mathrm{NPs}$ thin films at room temperature in (250-700) nm spectral range are measured and interpreted. Electron Scanning Microscope (SEM) (Quanta FEG 450) (FELMI-ZFE, Graz, Austria) is utilized to investigate the surface morphology of as-prepared thin films. Thermogravimetric analysis (TGA) technique is used to study thermal stability of as-synthesized doped polymeric thin films. To identify the major vibration modes and types of different bonding networks of the PMMA-PS/CeO nanocomposites, Fourier transform infrared spectroscopy (FTIR) (Bruker Vertex 80 and Hyperion 2000 microscope) (Bruker Optics, Karlsruhe, Germany) analysis is conducted.

\section{Result and Discussion}

\subsection{Optical Properties of PMMA-PS/Ce NPs Thin Film \\ 3.1.1. Transmittance and Reflectance}

UV-Vis spectrophotometer was used to explore and investigate the optical properties of PMMA-PS thin films doped with various Ce NPs concentrations. Figure 1 shows the transmittance of PMMA-PS/Ce NPs thin films. Analysis and interpretation of transmittance data can be partitioned into two spectral regions. Namely, low energy region $(700 \geq \lambda \geq 350) \mathrm{nm}$ in which all samples exhibit a high transparency of about $87 \%$. The high energy region $(250 \leq \lambda \leq 350) \mathrm{nm}$ is where transmittance starts to decay to a vanishing value. This region contains the absorption edge [46] that is red-shifted upon increasing the concentration of Ce NPs in the polymeric matrix suggesting a significant reduction of optical band gap energy of (PMMA-PS) $/ \mathrm{CeO}_{2}$ nanocomposite thin films [47]. The incorporation of $\mathrm{CeO}_{2} \mathrm{NPs}$ into polymeric matrix leads to a compression of the host matrix. Compressive strain introduced into PMMA-PS matrix can cause a red shift as a result of the changes of a built-in electric field. The polarization should be affected by doping and causes a red shift.

Figure 2 shows the reflectance of (PMMA-PS) $/ \mathrm{CeO}_{2}$ nanocomposite thin films. It can be clearly observed that reflectance of PMMA-PS, PMMA-PS $/ 1 \%, 3 \%, 5 \%$, and $7 \%$ $\mathrm{CeO}_{2} \mathrm{NPs}$ thin film exhibit values of $(7.6-10.1 \%),(9.2-9.8 \%),(9.3-10.2 \%),(8.7-10.4 \%),(9-$ $11.5 \%)$, respectively. 


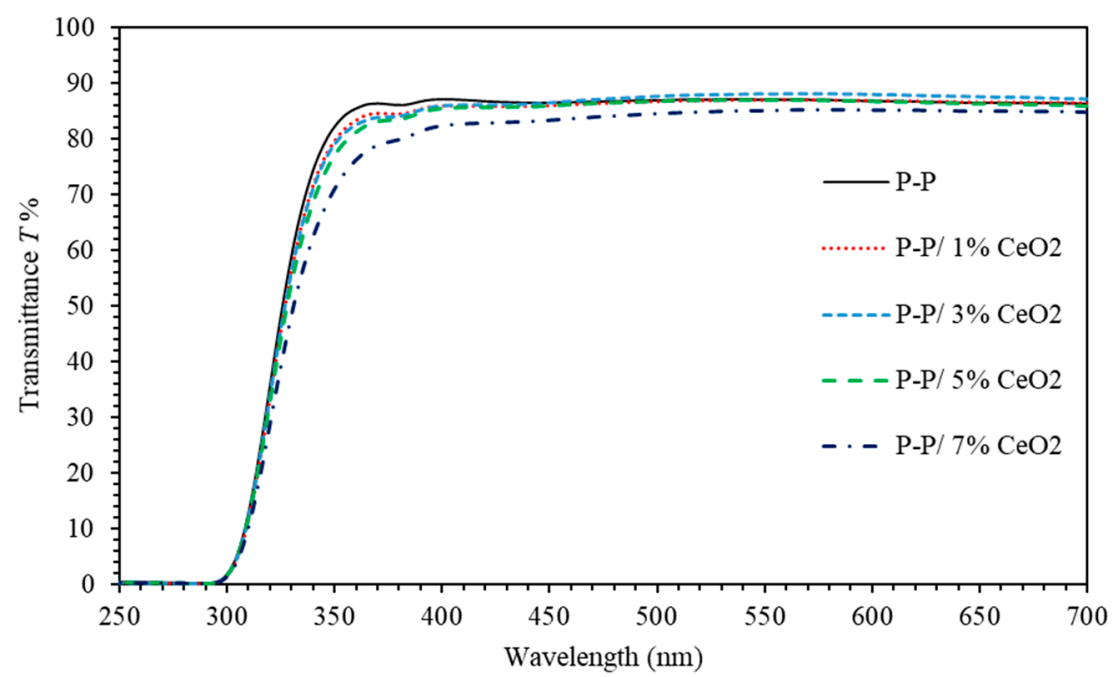

Figure 1. The transmittance of (PMMA-PS) $/ \mathrm{CeO}_{2}$ nanocomposite thin films incorporated with different $\mathrm{CeO}_{2}$ NPs concentrations.

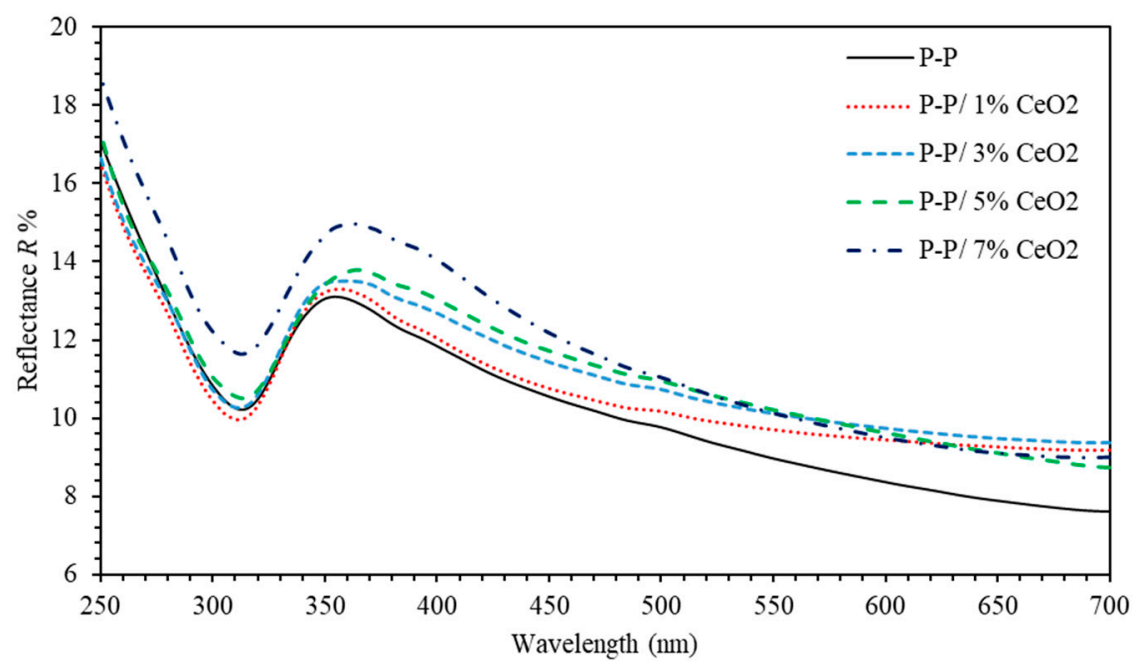

Figure 2. The reflectance of (PMMA-PS) $/ \mathrm{CeO}_{2}$ nanocomposite thin films with various $\mathrm{CeO}_{2} \mathrm{NPs}$ concentrations.

\subsubsection{Extinction Coefficient and Refractive Index}

The extinction coefficient $k$ for all samples was calculated using the formula $k=\alpha \lambda / 4 \pi$ where $\alpha$ is the absorption coefficient defined by $\alpha=(1 / d) \ln (1 / T)$ where $d$ is the thickness of thin films estimated to be $250 \mathrm{~nm}[48,49]$. The use of inorganic ceria nanoparticles into the polymer matrix can provide high-performance novel materials that find applications in many industrial fields. With this respect, frequently considered features are optical properties such as light absorption.

Figure 3 shows the extinction coefficient $k$ calculated in the spectral range $(250-700) \mathrm{nm}$ as a function of incident wavelength. For the spectral range $700 \geq \lambda \geq 350 \mathrm{~nm}, k$ exhibits a vanishing value for all investigated thin film samples; this means that thin films allow electromagnetic waves to pass through without any decay or damping for photons with wavelengths $\lambda \geq 350 \mathrm{~nm}$. In the high frequency regions, $250 \leq \lambda \leq 350 \mathrm{~nm}, k$ increases and attains a maximum value at $290 \mathrm{~nm}$. This can be attributed to extremely high absorption of the energetic EM waves in this region. Figure 3 indicates that such energetic EM waves having energies very close to the optical band gap energy of the nanocomposite thin film are largely absorbed. Exceptionally, (PMMA-PS) $/ \mathrm{CeO}_{2} 3 \%$ nanocomposite thin films 
exhibit the highest extinction coefficient indicating that energetic EM waves are completely absorbed in this case.

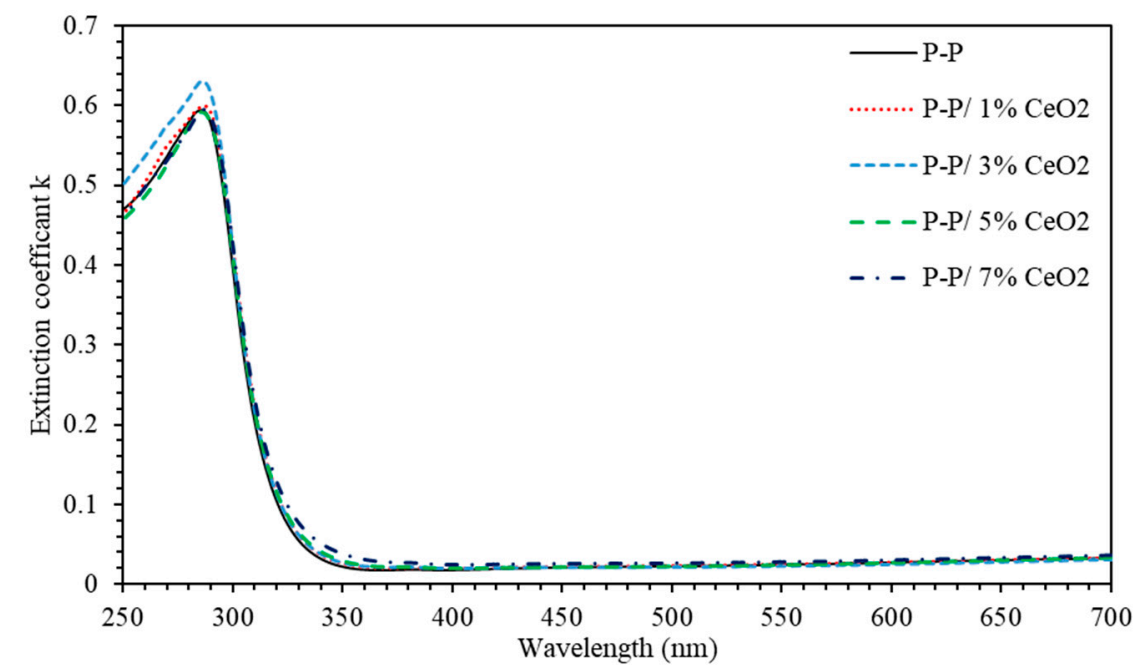

Figure 3. Extinction coefficient $k$ of (PMMA-PS) $/ \mathrm{CeO}_{2}$ nanocomposite thin films with various $\mathrm{CeO}_{2}$ NPs concentrations.

Refractive index $(n)$ is generally associated with the electronic polarization of ions and local field inside optical materials. Compared to inorganic solids, optical applications of polymers are often limited due to the relatively narrow range of the refractive index. Thus, the introduction of inorganic nanoparticles into a polymer matrix can result in polymeric nanocomposites with extreme refractive index, which finds potential applications in lenses, optical filters, reflectors, optical waveguides, optical adhesives, solar cells, or antireflection films. To elucidate a deeper insight into optical properties, refractive index $(N)$ is essentially composed of real part $(n)$ and imaginary part $(k) ;(N=n+i k)$ where $n=\left((1+R) /(1-R)+\sqrt{4 R\left(1-R^{2}\right)-k^{2}}\right.$ [50]. Figure 4 shows that $n$ of PMMA-PS exhibits values ranging between 1.76 and 2.13. Introducing $1 \%$ of $\mathrm{CeO}_{2} \mathrm{NPs}$ into polymeric matrix leads to a slight increase of $n(1.86-2.15)$. As the $\mathrm{CeO}_{2} \mathrm{NPs}^{2}$ concentrations is increased to $3 \%, 5 \%$, and $7 \%, n$ continuously increases to (1.88-2.15), (1.83-2.18) and (1.85-2.26). Consequently, (PMMA-PS)/ $\mathrm{CeO}_{2}$ nanocomposite thin films could be potential candidates as excellent reflective material [51].

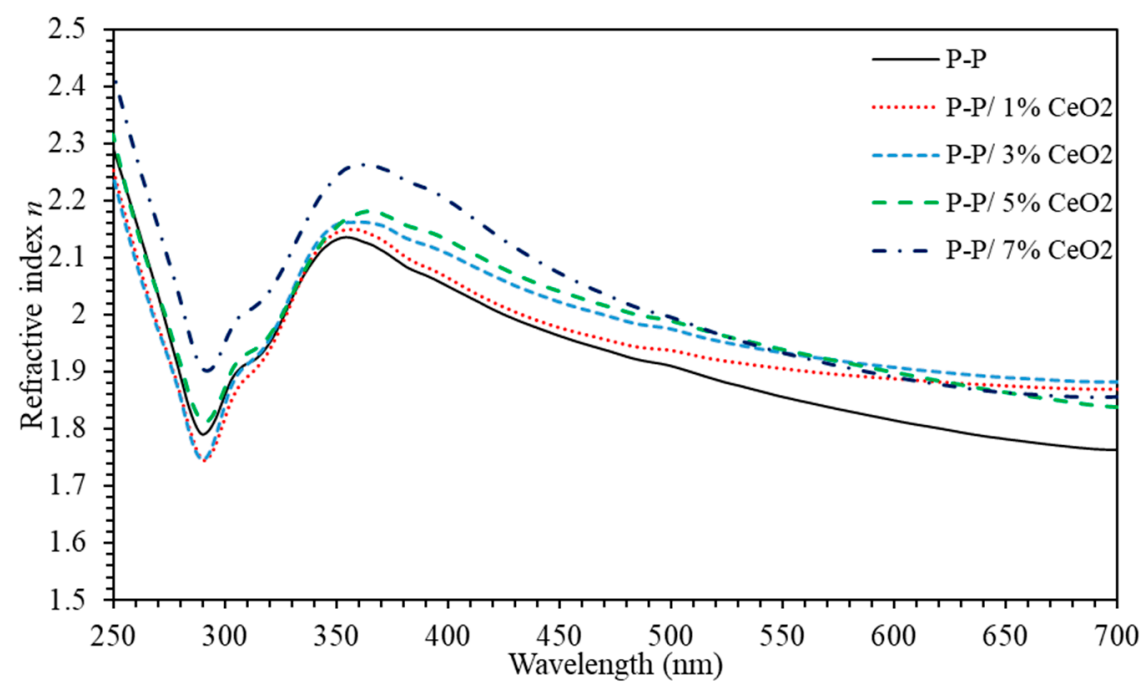

Figure 4. The refractive index $(n)$ of (PMMA-PS) $/ \mathrm{CeO}_{2}$ nanocomposite thin films with various $\mathrm{CeO}_{2}$ NPs concentrations. 


\subsubsection{Band Gap Energy Eg}

Optical band gap energy $E_{g}$ of as-prepared doped thin films is investigated using Tauc plot model. According to this model, $(\alpha h v)=B\left(h v-E_{g}\right)^{(1 / 2)}$, where $B$ is a constant related to the type of the thin film. Figure 5 shows the relationship between the energy of incident photons $(E=h v)$ and $(\alpha h v)^{2}$. The optical band gap energy $E_{g}$ of (PMMAPS) $/ \mathrm{CeO}_{2}$ nanocomposite thin films with various $\mathrm{CeO}_{2} \mathrm{NPs}$ concentrations is obtained by extrapolating the liner part of Tauc plot to the interception of the incident photon energy $(h v)$. The obtained optical band gap energy of PMMA-PS is calculated to be $E_{g}=4.03 \mathrm{eV}$ consistent with previously reported values $[52,53]$. As the $\mathrm{CeO}_{2} \mathrm{NPs}$ concentrations is increased to $1 \%, 3 \%, 5 \%$, and $7 \%$, optical band gap decreases to $3.97 \mathrm{eV}, 3.76 \mathrm{eV}, 3.63 \mathrm{eV}$, and $3.6 \mathrm{eV}$ respectively. Thus, band gap engineering could be achieved effectively by inserting a specific concentration of $\mathrm{CeO}_{2} \mathrm{NPs}$ in the polymeric thin films.
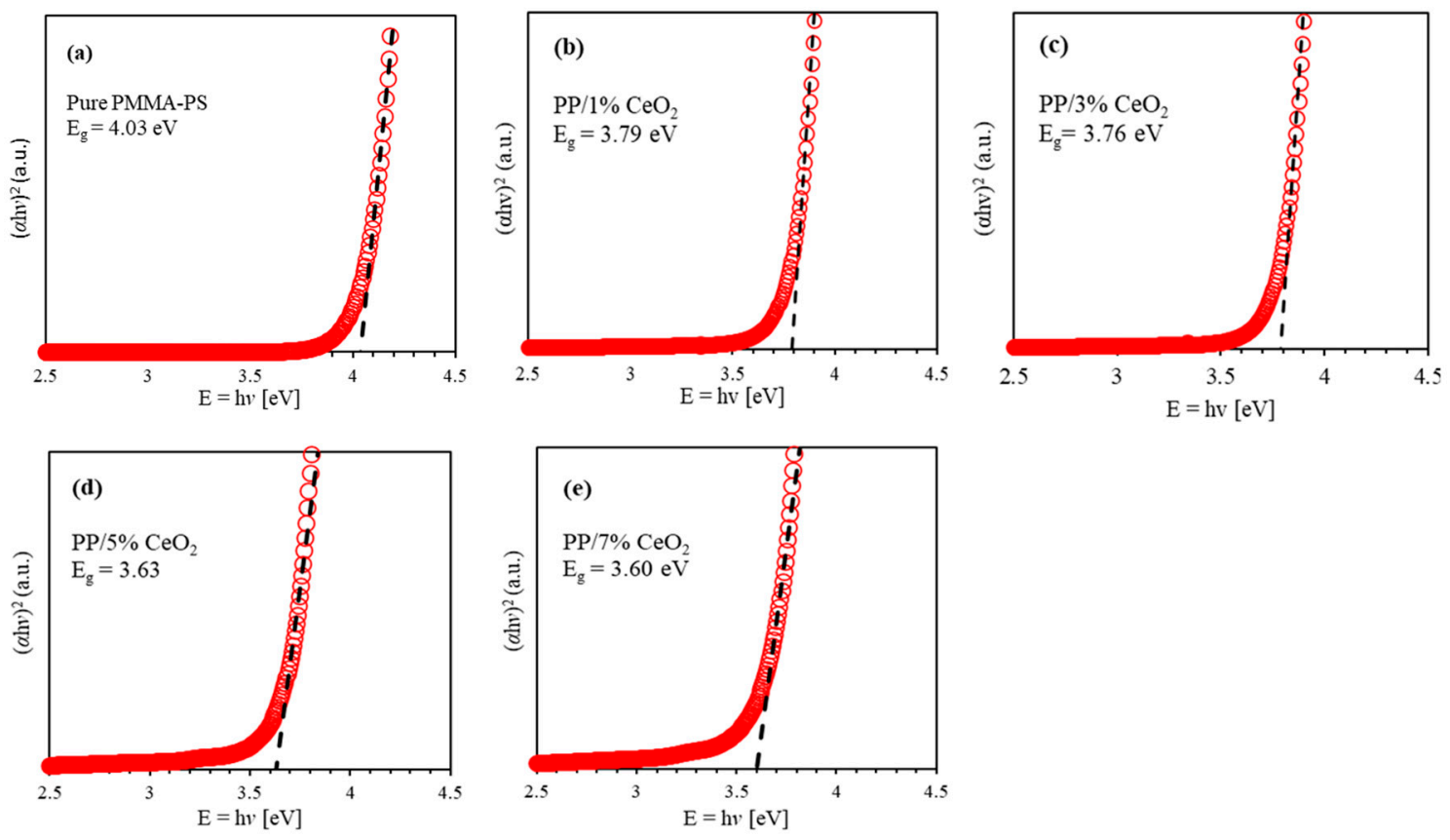

Figure 5. The Tauc plot for energy band gap $E_{g}$ of (PMMA-PS) $/ \mathrm{CeO}_{2}$ nanocomposite thin films containing various $\mathrm{CeO} 2$ NPs concentrations. (a) Band gap of Pure PMMA-PS; (b) Band gap of PMMA-PS $/ 1 \% \mathrm{CeO}_{2} ;$ (c) Band gap of PMMA-PS/3\% $\mathrm{CeO}_{2} ;$ (d) Band gap of PMMA-PS/5\% $\mathrm{CeO}_{2} ;$ (e) Band gap of PMMA-PS/5\% $\mathrm{CeO}_{2}$.

Refractive index dispersion is one of the most crucial parameters. Moreover, calculating dispersion energies is essential to obtain a deeper insight into the applications of (PMMA-PS) $/ \mathrm{CeO}_{2}$ nanocomposite thin films for optical devices [51]. Therefore, refractive index and dispersion energies must be studied carefully to specify the potential application of the material [54].

Figure 6 shows optical band gap energy $E_{g}$ plotted versus $\mathrm{CeO}_{2} \mathrm{NPs}$ concentration $(\%)$. It can be noticed that $E_{g}$ decreases exponentially with ceria NPs concentration.

\section{Wemple DiDomenico Model}

Wemple DiDomenico model (WDD) is a classical single effective-oscillator model. This model can be utilized to calculate key optical dispersion parameters such as effective single oscillator energy $E_{o}$ and dispersion energy $E_{d}$ for certain optical materials. The $E_{o}$ parameter provides essential information about the band structure of the polymeric thin film, while $E_{d}$ is associated with the mean potency of interband photosensitive transitions and the structural fluctuations [55]. Furthermore, WDD model can be employed to estimate other optical parameters such as the zero frequency-refractive index $\left(n_{0}\right)$, zero-frequency 
dielectric constant $\varepsilon_{0}$, and the spectral moments $M_{-1}$ and $M_{-3}$. The relationships of different parameters can be expressed as,

$$
\left(n^{2}-1\right)=\frac{E_{d} E_{0}}{E_{0}^{2}-h v^{2}}
$$

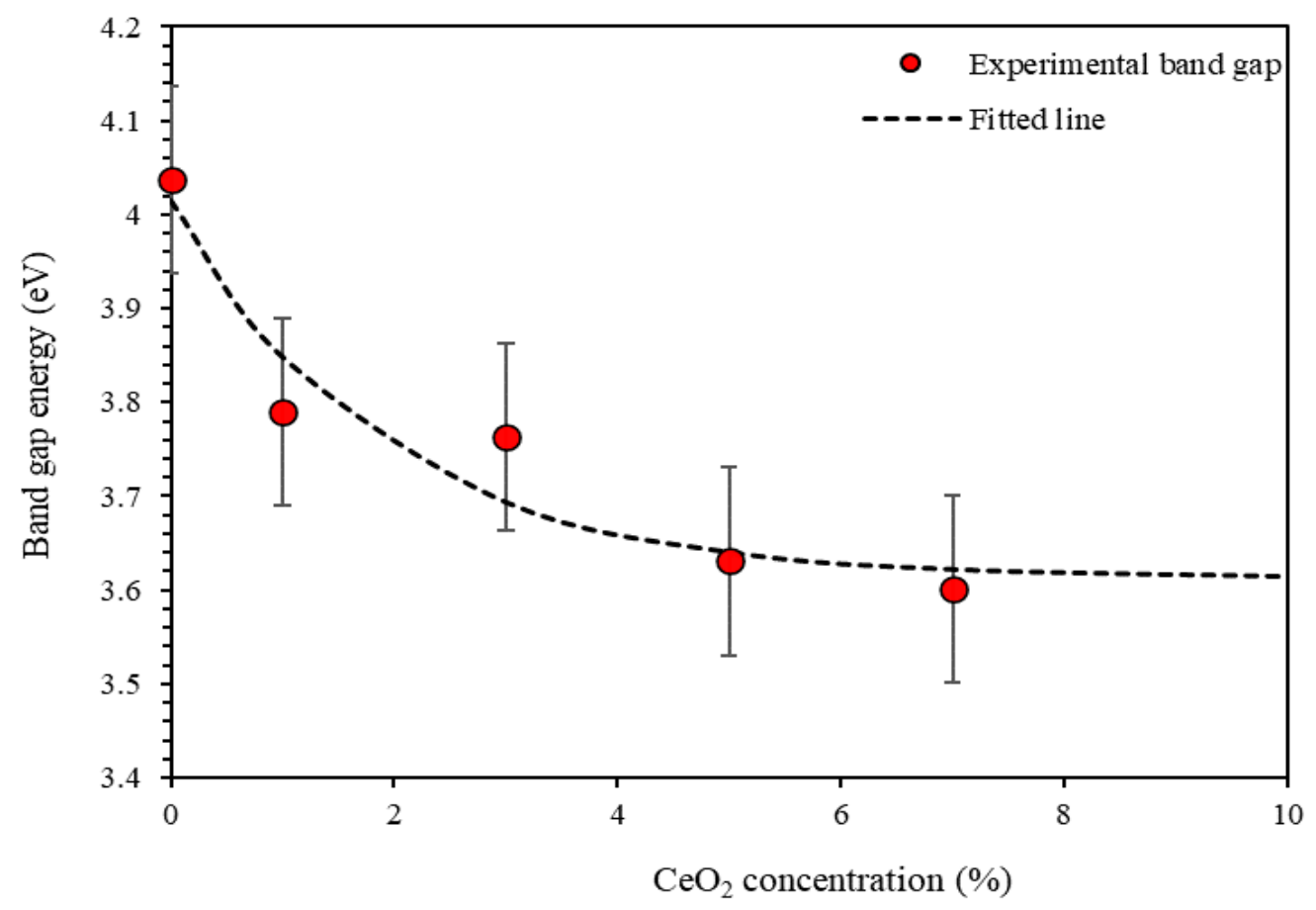

Figure 6. The energy band gap $E_{g}$ of PMMA-PS as a function of $\mathrm{CeO}_{2}$ concentration.

Equation (1) can be rewritten as,

$$
\left(n^{2}-1\right)^{-1}=\frac{E_{0}}{E_{d}}-\frac{h v^{2}}{E_{0} E_{d}}
$$

The energy of incident photon $(h v)$ can be plotted against $\left(n^{2}-1\right)^{-1}$ to obtain the values of dispersion parameters from the slope of the obtained straight line $\left(E_{d} E_{o}\right)^{-1}$ and the interception with the vertical axis $\left(E_{0} / E_{d}\right)$. Figure $7 \mathrm{a}$,b display $\left(n^{2}-1\right)^{-1}$ versus $(h v)^{2}$ and $\left(n^{2}-1\right)^{-1}$ versus $(\lambda)^{-2}$ of (PMMA-PS) $/ \mathrm{CeO}_{2}$ nanocomposite thin films incorporated with various concentrations of $\mathrm{CeO}_{2}$ NPs. The values of the two important dispersion parameters $E_{d}$ and $E_{o}$ obtained from the two plots are listed in Table 1. Careful inspection of the values of $E_{d}$ and $E_{o}$ parameters of PMMA-PS are found to be $6.893 \mathrm{eV}$ and $4.063 \mathrm{eV}$, respectively. The corresponding attained values of (PMMA-PS) $/ \mathrm{CeO}_{2} 1 \%$ are $14.484 \mathrm{eV}$ and $6.333 \mathrm{eV}$, indicating a significant increase as only a small concentration of $\mathrm{CeO}_{2} \mathrm{NPs}$ are incorporated into polymeric films.

By rewriting Equation (2) and setting $h v=0$ [56], the $\varepsilon_{0}$ and $\left(n_{0}\right)$ are related by the formula,

$$
\varepsilon_{0}=n_{0}^{2}=1+\frac{E_{d}}{E_{0}}
$$

The obtained values of $\varepsilon_{0}$ are presented in Table 1 . The calculated values of $n_{0}$ are consistent with the theoretical and the experimental values of the normal refractive index. The estimated values of $\varepsilon_{0}$ and $n_{0}$ of PMMA-PS are found to be 2.696 and 1.642, respectively. Introducing $\mathrm{CeO}_{2}$ NPs into PMMA-PS boost the values of $\varepsilon_{0}$ and $n_{0}$ for all investigated thin film samples. In addition, the interplay between $E_{d}, E_{o}$ and the optical oscillator 
strength $(f)$ of the optical transition between the initial state and the final state can be expressed as $f=E_{d} E_{o}[57,58]$. The obtained values of $f$ are displayed in Table 1. Moreover, the effective single oscillator moments $M_{-1}$ and $M_{-3}$ can be correlated with dispersion parameters [59-61].

$$
\begin{aligned}
E_{0}^{2} & =\frac{M_{-1}}{M_{-3}} \\
E_{d}^{2} & =\frac{M_{-3}^{3}}{M_{-1}}
\end{aligned}
$$
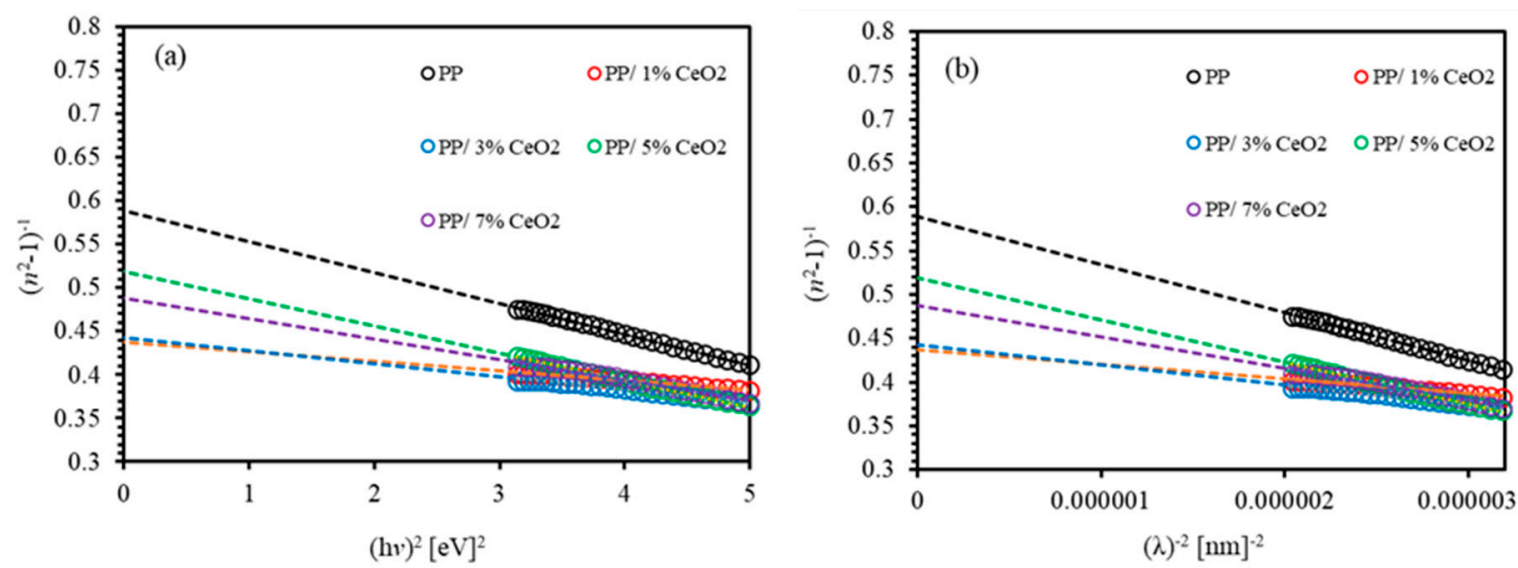

Figure 7. (a) The $\left(n^{2}-1\right)^{-1}$ versus $(h v)^{2}$; (b) The $\left(n^{2}-1\right)^{-1}$ versus $(\lambda)^{-2}$ of (PMMA-PS) $/ \mathrm{CeO}_{2}$ nanocomposite thin films with various $\mathrm{CeO}_{2} \mathrm{NPs}$ concentrations.

\begin{tabular}{|c|c|c|c|c|c|}
\hline Parameter & P-P & $\mathrm{P}-\mathrm{P} / \mathbf{1} \% \mathrm{CeO}_{2} \mathrm{NPs}$ & $\mathrm{P}-\mathrm{P} / 3 \% \mathrm{CeO}_{2} \mathrm{NPs}$ & $\mathrm{P}-\mathrm{P} / 5 \% \mathrm{CeO}_{2} \mathrm{NPs}$ & $\mathrm{P}-\mathrm{P} / 7 \% \mathrm{CeO}_{2} \mathrm{NPs}$ \\
\hline Dispersion energy $E_{d}(\mathrm{eV})$ & 6.893 & 14.484 & 12.268 & 7.832 & 9.288 \\
\hline $\begin{array}{l}\text { Effective single oscillator } \\
\qquad E_{0}(\mathrm{eV})\end{array}$ & 4.063 & 6.333 & 5.433 & 4.065 & 4.542 \\
\hline $\begin{array}{l}\text { Zero-frequency refractive } \\
\text { index } n_{0}\end{array}$ & 1.642 & 1.812 & 1.804 & 1.710 & 1.744 \\
\hline $\begin{array}{l}\text { Zero-frequency dielectric } \\
\text { constant } \varepsilon_{0}\end{array}$ & 2.696 & 3.286 & 3.257 & 2.926 & 3.044 \\
\hline $\begin{array}{l}\text { Optical oscillator strength } \\
\qquad f(\mathrm{eV})^{2}\end{array}$ & 28.011 & 91.743 & 66.666 & 31.847 & 42.194 \\
\hline Optical moments $M_{-1}$ & 1.696 & 2.286 & 2.257 & 1.926 & 2.044 \\
\hline $\begin{array}{l}\text { Optical moments } M_{-3} \\
\left(\mathrm{eV}^{-2}\right)\end{array}$ & 0.102 & 0.056 & 0.076 & 0.116 & 0.099 \\
\hline $\begin{array}{l}\text { Oscillator length strength } \\
\qquad S_{0} \times \mathbf{1 0}^{-5}\end{array}$ & 1.804 & 5.728 & 4.139 & 2.119 & 2.523 \\
\hline $\begin{array}{c}\text { Average oscillator } \\
\text { wavelength } \lambda_{0}\end{array}$ & 306.200 & 199.389 & 232.683 & 302.325 & 282.096 \\
\hline Urbach energy $E_{U}(\mathrm{meV})$ & 182.495 & 186.216 & 187.360 & 194.476 & 207.675 \\
\hline
\end{tabular}

Table 1. Some optical parameters for PMMA-PS and PMMA-PS incorporation with $\mathrm{CeO}_{2} \mathrm{NPs}$

As demonstrated by Table 1 , the values of optical moments $M_{-1}$ and $M_{-3}$ of PMMAPS are obtained to be 1.696 and $0.102\left(\mathrm{eV}^{-2}\right)$, respectively; while for (PMMA-PS) $/ 1 \% \mathrm{CeO}_{2}$ NPs, the value of $M_{-1}$ increases to 2.286 and the value of $M_{-3}$ decreases to $0.056 \mathrm{eV}^{-2}$. This behavior could be explained in terms of the significant decrease in the polarization of (PMMA-PS) $/ \mathrm{CeO}_{2}$ NPs nanocomposite thin films [62]. 


\section{Sellmeier Oscillator Parameters}

From another perspective, we employ Sellmeier oscillator model to elucidate the dispersion in thin films in terms of the average oscillator wavelength $\left(\lambda_{0}\right)$ and on the oscillator length strength $\left(S_{0}\right)$. Refractive index and the squared wavelength at higher wavelength are related to $\lambda_{0}$ and $S_{0}$ by the formula,

$$
n^{2}-1=\frac{\left(S_{0} \lambda_{0}\right)}{1-\left(\lambda_{0} / \lambda^{2}\right)}
$$

By plotting $\left(n^{2}-1\right)^{-1}$ versus $\lambda^{-2}$, we calculate $S_{0}$ from the slope of the resulting straight line $\left(1 / S_{0}\right)$. The values of $\left(\lambda_{0}\right)$ can be obtained from the intercept with the vertical axis $\left(1 / \lambda_{0}^{2} S_{0}\right)$ as can be clearly seen from Figure $7 \mathrm{~b}$. It clearly shows that the refractive index at higher wavelength adopts Sellmeier's dispersion relation. The calculated values of $S_{0}$ and $\lambda_{0}$ are tabulated in Table 1 . It reveals that $S_{0}$ and $\lambda_{0}$ of PMMA-PS are found to be $306.200 \times 10^{-5}$ and $306.200 \mathrm{~nm}$, respectively. For PMMA-PS/CeO $\mathrm{CPs}_{2}$ nanocomposites $S_{0}$ decreases and $\lambda_{0}$ increases. These tendencies hold up to $5 \%$ of $\mathrm{CeO}_{2} \mathrm{NPs}$ incorporated into polymeric films.

\section{Urbach Energy}

To obtain a deeper insight into optical properties of thin films, order of crystallinity for PMMA-PS $/ \mathrm{CeO}_{2}$ nanocomposite thin films is investigated by calculating Urbach energy $E_{U}$. The absorption coefficient is related to $E_{U}$ via $\alpha=\alpha_{0} \exp \left(h v / E_{U}\right)$, where $\alpha_{0}$ is a constant. By plotting $\ln (\alpha)$ versus incident photon energy $(h v), E_{U}$ can be determined by extrapolating the straight line below the absorption band edge. The estimated values of $E_{U}$ of PMMA-PS $/ \mathrm{CeO}_{2}$ nanocomposite samples are presented in Table 1. For unloaded PMMA-PS thin film, $E_{U}$ is found to be $182.495 \mathrm{meV}$. It is observed that value of $E_{U}$ of PMMA-PS $/ 7 \% \mathrm{CeO}_{2}$ has increased to $207.675 \mathrm{meV}$ suggesting a significant disorder and surface interactions in the polymeric thin films loaded with ceria nanoparticles.

\subsection{FTIR Analysis}

Fourier Transform Infrared Spectroscopy (FTIR) is employed to explore and identify the vibrational bands of the loaded PMMA-PS thin films. Figure 8 shows the FTIR spectra of PMMA-PS and PMMA-PS doped by $\mathrm{CeO}_{2}$ NPs. The vibrational bands observed in the FTIR spectrum are typical of those of PMMA and PS polymers. The vibrational bands associated with bending of C-H bonds are registered in the $1000-700 \mathrm{~cm}^{-1}$ spectral range. The vibrational bands located in the $1000-1300 \mathrm{~cm}^{-1}$ range are assigned to $\mathrm{C}-\mathrm{O}$ stretching. The vibrational bands recorded in between $1300-1400 \mathrm{~cm}^{-1}$ are assigned to $-\mathrm{CH}_{3}$ bending, while a band at $1449 \mathrm{~cm}^{-1}$ could be ascribed to the $-\mathrm{CH}_{2}$ bending. Band at $1484 \mathrm{~cm}^{-1}$ could be ascribed to the $\mathrm{C}=\mathrm{C}$ bonds. The bands appearing between 1600$1800 \mathrm{~cm}^{-1}$ are associated with $\mathrm{C}=\mathrm{O}$ bonds. Bands identified between $2800-3200 \mathrm{~cm}^{-1}$ are allocated to the $\mathrm{C}-\mathrm{H}$ stretching. The six IR bands located in the $1000-1300 \mathrm{~cm}^{-1}$ spectral range are associated with $\mathrm{C}-\mathrm{O}$ vibrational modes. As the dipole moment changes due to the vibrations of atoms, two IR bands are associated with symmetric stretch, two with asymmetric stretch and two with the $\mathrm{C}-\mathrm{O}$ bending. The wide spectral range identifies the locations of different IR bands in the nanocomposite thin films. Finally, the peak appearing at $541.42 \mathrm{~cm}^{-1}$ in the nanocomposites is clearly associated with Ce-O suggesting homogenous incorporation of $\mathrm{CeO}_{2} \mathrm{NPs}$ into the co-polymer's matrices. Furthermore, significant changes observed in width and intensity of the vibrational bands of PMMA-PS upon addition of $\mathrm{CeO}_{2}$ NPs indicate the strong influence of ceria NPs on the spectroscopy of the blended polymer. Table 2 presents the peak positions of all major vibrational bands of PMMA-PS doped by $\mathrm{CeO}_{2}$ NPs. The two main factors that influence the intensity of an IR absorption band are the intermolecular bonding between PMMA-PS matrix and Ce NPs as well as the change in dipole moment that occurs during a vibration. 

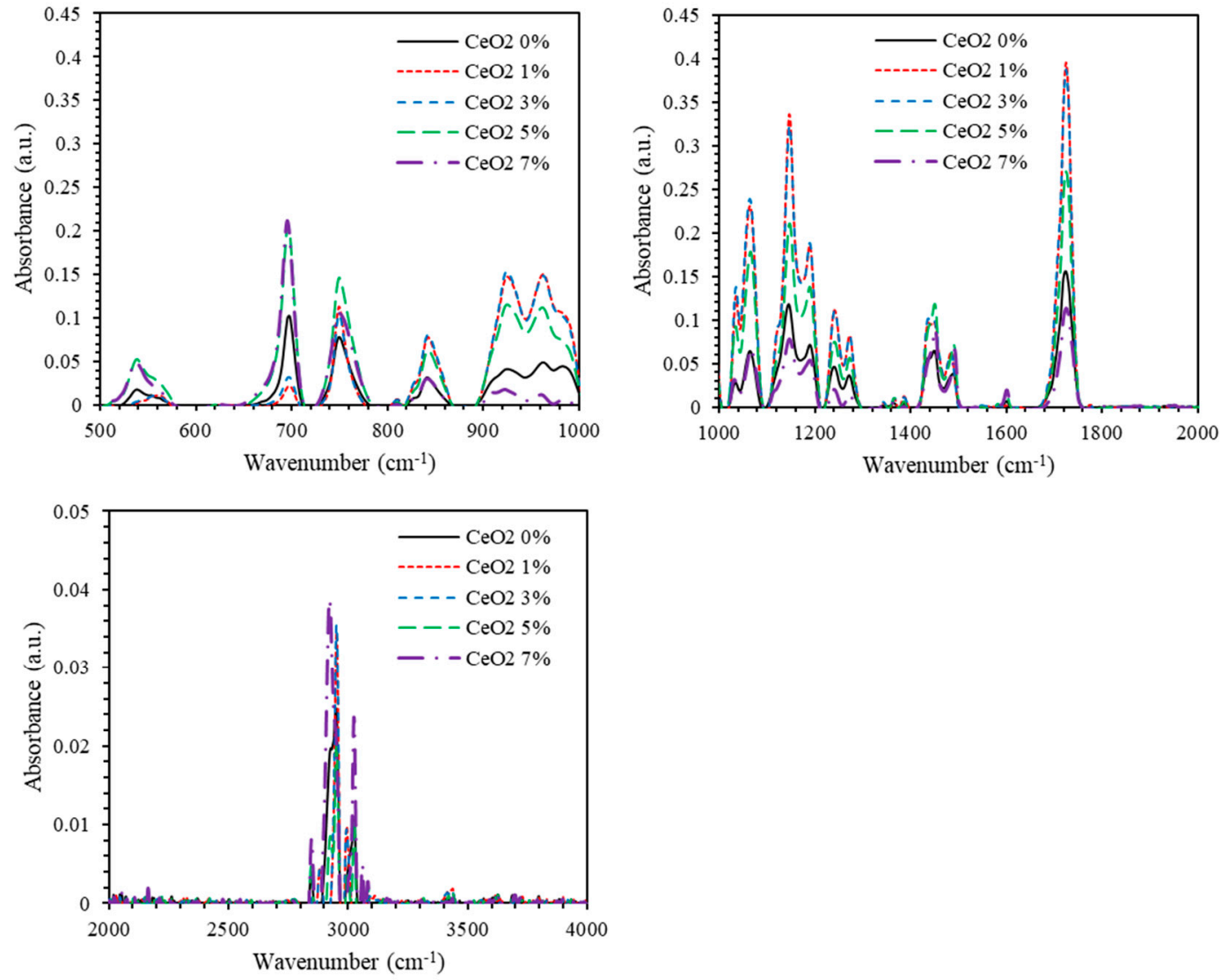

Figure 8. The FTIR spectra of PMMA-PS, and PMMA-PS doped by $\mathrm{CeO}_{2}$ NPs.

\subsection{Thermogravimetric Analysis (TGA)}

To elucidate thermal stability of doped polymeric thin films investigated in this study, thermogravimetric analysis (TGA) (weight loss \%) with respect to temperature and derivative thermogravimetric analysis (DTG) are measured for PMMA-PS, and PMMA-PS incorporated $\mathrm{CeO}_{2}$ NPs. A weight loss and differential thermogravimetry curve (first derivative of the weight with respect to temperature) of PMMA-PS and PMMA-PS incorporated $\mathrm{CeO}_{2} \mathrm{NPs}$ are shown in Figure 9. Two main regions of weight loss and first derivative weight loss are observed. The first is identified in the $100-200{ }^{\circ} \mathrm{C}$ range. In this region, the estimated weight loss is estimated to be $3-12 \%$ that could be attributed to adsorbed water. In the second region, mainly observed between $300{ }^{\circ} \mathrm{C}$ and $400{ }^{\circ} \mathrm{C}$, the weight loss decreases from $90 \%$ to $20 \%$. Such a large weight loss is clear indication of thermal decomposition suggesting that doped polymeric thin films exhibit low chemical stability at high temperature. Furthermore, a maximum rate of weight loss is observed at $330{ }^{\circ} \mathrm{C}$, for PMMA-PS thin films. This maximum rate shifts slightly towards a high temperature region as the concentration of $\mathrm{CeO}_{2}$ NPs inserted into PMMA-PS matrix is increased.

Figures 10 and 11 show the FTIR spectra of PMMA-PS and PMMA-PS/5\%CeO for thin film samples processed at different annealing temperatures. For thin film samples annealed at temperatures $200-400{ }^{\circ} \mathrm{C}$, absorbance of both PMMA-PS and PMMA-PS/CeO exhibits a sharp shrink away. This could be attributed to the elimination of $\mathrm{C}-\mathrm{H}$ bending of PMMA-PS, and C-H bending and C-O stretching of PMMA-PS/5\% $\mathrm{CeO}_{2}$. 


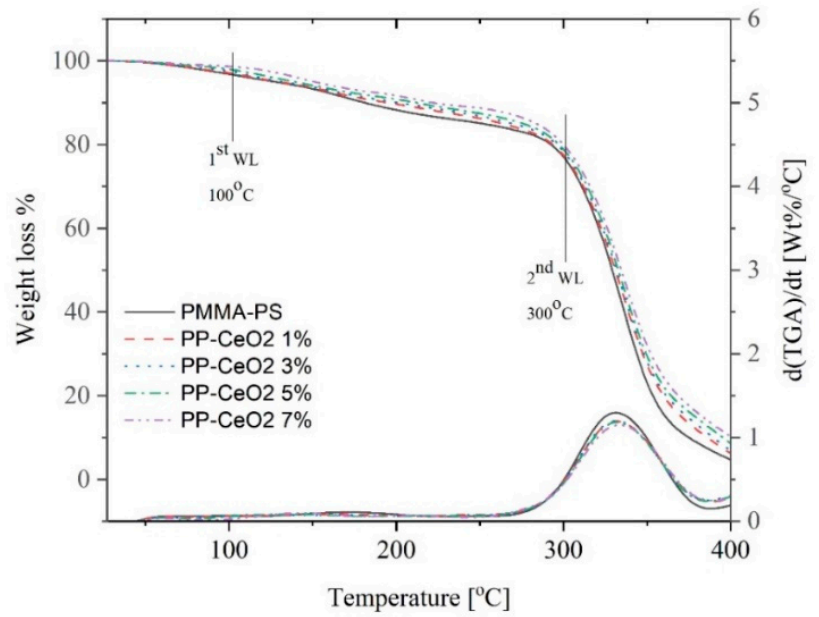

Figure 9. The weight loss and 1st derivative of weight loss of PMMA-PS incorporated with different concentrations of $\mathrm{CeO}_{2}$ NPs as a function of temperature.
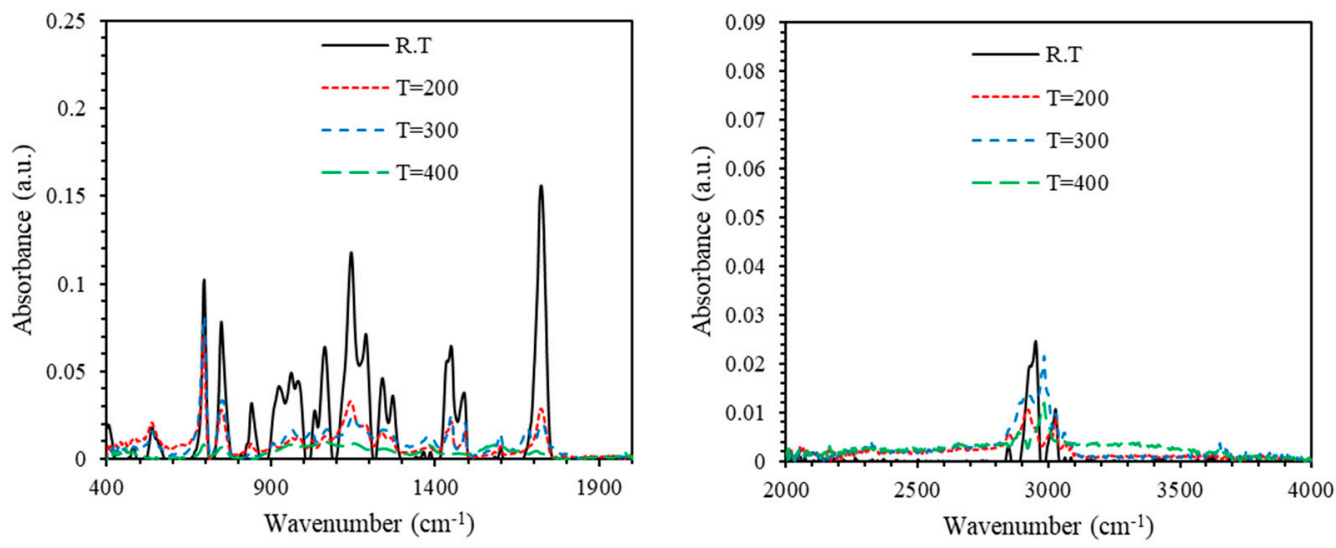

Figure 10. The absorbance of PMMA-PS processed at different annealing temperatures.
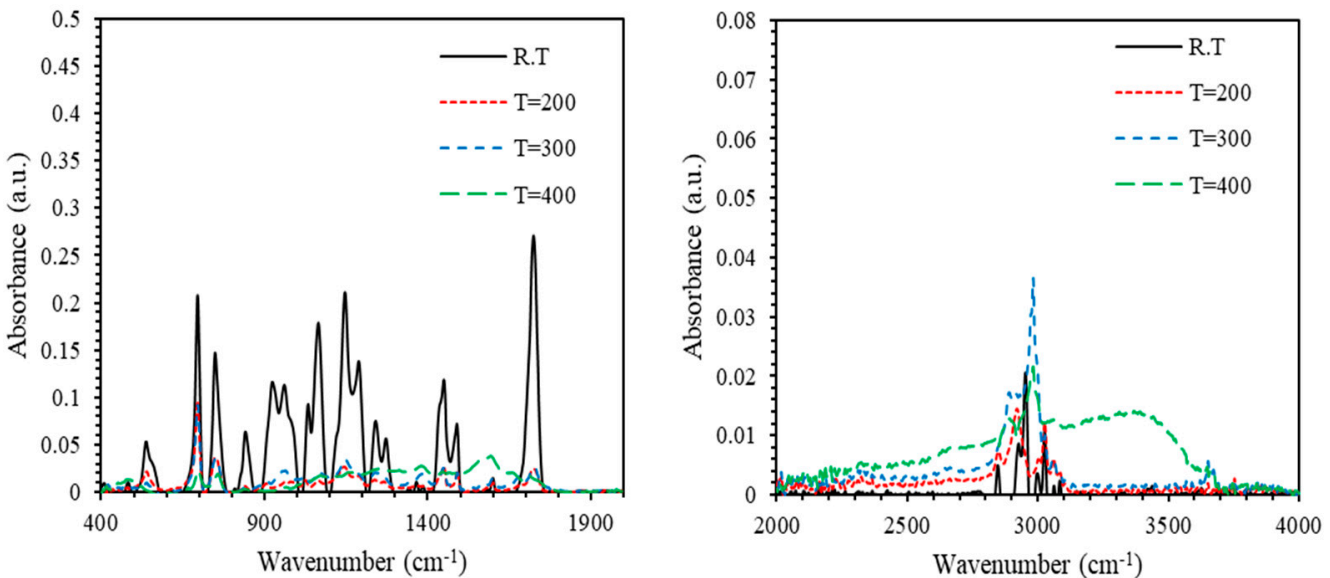

Figure 11. The absorbance of PMMA-PS $/ 5 \% \mathrm{CeO}_{2}$ processed at different annealing temperatures.

\subsection{Surface Morphology of PMMA-PS/CeO $\mathrm{O}_{2}$ Thin Films}

The ability to control the orientation of block copolymer thin film features relative to the surface is key to the material's usefulness for patterning. For example, a surface appears as meandering fingerprint line/space patterns for $\mathrm{CeO}_{2}$ to be homogenously inserted and distributed. For PMMA-PS, several well-established and effective surface pre-treatments for dictating the domain orientations of self-assembled patterns are essentially possible. Even 
with appropriate surface pre-treatments, self-assembly of PMMA-PS patterns are relatively sensitive to the concentration of $\mathrm{CeO}_{2} \mathrm{NPs}$. Exciting recent advances in block copolymerbased patterning have used self-assembly to achieve alignment and registration of features by directing meandering self-assembled fingerprint patterns. Surface morphology of (PMMA-PS) $/ \mathrm{CeO}_{2} \mathrm{NPs}$ at $20 \mu \mathrm{m}$ magnification are presented in Figure 12. Figure 12a shows that undoped PMMA-PS thin films exhibit an organized texture. Figure $12 \mathrm{~b}-\mathrm{d}$ show a small effect of the $\mathrm{CeO}_{2}$ NPs immersed into thin film matrix on the surface of doped PMMA-PS nanocomposite thin films. Furthermore, we examine SEM micrographs to investigate the morphology and dispersion of $\mathrm{CeO}_{2}$ NPs on the surface of PMMA-PS films. Good dispersion of $\mathrm{CeO}_{2}$ NPs on the surface of the PMMA-PS thin films is revealed. This provides a substantial evidence of the validity of our synthesis process of obtaining $\mathrm{CeO}_{2}$ NPs. SEM images indicate that measured size of $\mathrm{CeO}_{2} \mathrm{NPs}$ is in $25-50 \mathrm{~nm}$.
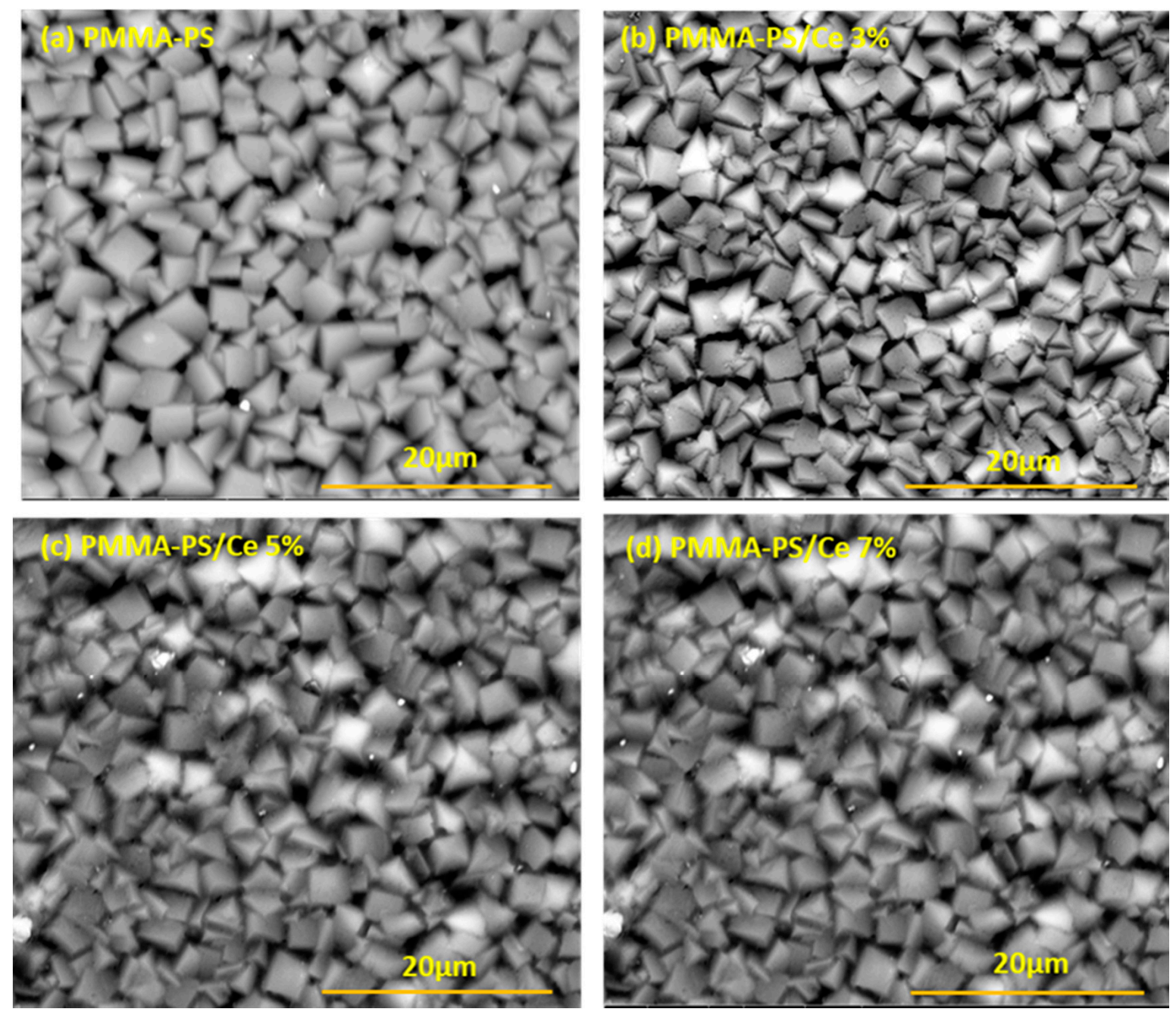

Figure 12. SEM (scanning electron microscope) cross sections of chemically developed images of thin-films of (a) PMMAPS (polymethyl methacrylate-polystyrene) block copolymers, (b) PMMA-PS/CeO $3 \%$, (c) PMMA-PS/CeO $5 \%$, and (d) PMMA-PS $/ \mathrm{CeO}_{2} 7 \%$. 
Table 2. The peak positions of all vibrational bands of PMMA-PS, and PMMA-PS doped with $\mathrm{CeO}_{2}$ NPs.

\begin{tabular}{|c|c|c|c|c|c|}
\hline $\begin{array}{c}\text { Vibrational } \\
\text { Band }\end{array}$ & PMMA-PS & $\begin{array}{c}\text { PMMA- } \\
{\mathrm{PS} / \mathrm{CeO}_{2}} \\
1 \%\end{array}$ & $\begin{array}{c}\text { PMMA- } \\
{\mathrm{PS} / \mathrm{CeO}_{2}}_{3 \%}\end{array}$ & $\begin{array}{c}\text { PMMA- } \\
{\mathrm{PS} / \mathrm{CeO}_{2}}_{5 \%}\end{array}$ & $\begin{array}{c}\text { PMMA- } \\
{\mathrm{PS} / \mathrm{CeO}_{2}} \% \\
7 \%\end{array}$ \\
\hline \multirow{5}{*}{$\mathrm{C}-\mathrm{H}$ bending } & - & 541.42 & 541.42 & 541.42 & 541.42 \\
\hline & 704.03 & 706.03 & 693.74 & 697.86 & 697.86 \\
\hline & 753.44 & 7.45 .20 & 753.44 & 751.38 & 753.44 \\
\hline & 841.96 & 844.02 & 844.02 & 844.02 & 841.96 \\
\hline & 965.47 & 963.41 & 963.41 & 963.41 & 963.41 \\
\hline \multirow{6}{*}{$\begin{array}{c}\mathrm{C}-\mathrm{O} \\
\text { stretching }\end{array}$} & 1035.46 & 1037.52 & 1037.52 & 1037.52 & 1035.46 \\
\hline & 1068.40 & 1068.40 & 1066.34 & 1068.40 & 1070.46 \\
\hline & 1148.68 & 1148.68 & 1148.68 & 1148.68 & 1150.47 \\
\hline & 1187.79 & 1191.91 & 1191.91 & 1191.91 & 1191.91 \\
\hline & 1251.61 & 1243.38 & 1243.38 & 1245.44 & 1245.44 \\
\hline & 1280.43 & 1274.26 & 1274.26 & 1276.32 & 1276.32 \\
\hline \multirow{2}{*}{$\begin{array}{c}-\mathrm{CH}_{3} \\
\text { bending }\end{array}$} & 1371.01 & 1366.89 & 1366.89 & 1366.89 & 1368.95 \\
\hline & 1389.54 & 1385.42 & 1387.48 & 1385.42 & 1385.42 \\
\hline $\begin{array}{c}-\mathrm{CH}_{2} \\
\text { bending }\end{array}$ & 1449.24 & 1451.29 & 1447.18 & 1449.24 & 1451.29 \\
\hline $\mathrm{C}=\mathrm{C}$ & 1484.23 & 1486.29 & 1486.29 & 1490.41 & 1492.47 \\
\hline \multirow{2}{*}{$\mathrm{C}=\mathrm{O}$} & 1601.57 & 1599.51 & 1603.63 & 1603.63 & 1601.57 \\
\hline & 1725.03 & 1725.08 & 1725.08 & 1725.08 & 1725.08 \\
\hline $\begin{array}{c}\mathrm{C}-\mathrm{H} \\
\text { stretching }\end{array}$ & $2800-3200$ & $2800-3200$ & $2800-3200$ & $2800-3200$ & $2800-3200$ \\
\hline
\end{tabular}

\section{Conclusions}

In summary, (PMMA-PS) $/ \mathrm{CeO}_{2}$ nanocomposite thin films doped with different concentrations of $\mathrm{CeO}_{2}-\mathrm{NPs}(0$ to $7 \%$ ) are synthesized and deposited on glass substrates via dip-coating technique. As-grown thin films are investigated to elucidate the spectral behavior of key optical parameters such as transmittance, reflectance, absorption coefficient, refractive index, and extinction coefficient. Furthermore, a combination of classical models such as Tauc, Wemple DiDomenicol, and Sellmeier oscillator models are employed to calculate the optical band gap energy, dispersion parameters, and optoelectronic parameters of the loaded (PMMA-PS) thin films. Un-doped PMMA-PS exhibits a high transparency of about $87 \%$. The transmittance decreases dramatically to a vanishing value in the high energy region $(250 \leq \lambda \leq 350) \mathrm{nm}$. Reflectance is found to increase as the concentration of ceria NPs loads increases. Furthermore, refractive index $n$ of PMMA-PS exhibits values ranging between 1.76 and 2.13. Interestingly, introducing $7 \%$ of $\mathrm{CeO}_{2} \mathrm{NPs}_{\text {into }}$ polymeric matrix leads to a slight increase of $n$ to 1.85-2.26. Therefore, PMMA-PS/CeO nanocomposite could be used for high reflective coatings and candidates for strong optical confinement applications. The optical band gap obtained of PMMA-PS copolymers thin films is $\approx 4.03$ indicating that it is an insulating dielectric material. Introducing $\mathrm{CeO}_{2}$ nanoparticles into the copolymers matrix decreases the optical band gap and thus it is possible to engineer the optical properties of this novel material. To elucidate a deeper understanding of the vibrational modes of $\mathrm{PMMA}-\mathrm{PS} / \mathrm{CeO}_{2}$ nanocomposite thin films, we carry out FTIR measurements. We identify and interpret all vibrational bands associated with formation, rotation, and twisting of different bonds involved in the investigated polymerized thin film. Evidently, major changes are observed in width and intensity of the vibrational bands of PMMA-PS upon merging of $\mathrm{CeO}_{2} \mathrm{NPs}$ in copolymers matrix. In addition, TGA and DTG studies demonstrate that introducing higher concentrations of $\mathrm{CeO}_{2}$ NPs into PMMA-PS nanocomposite enhances thermal stability significantly. Surface morphology of PMMA-PS/ $\mathrm{CeO}_{2}$ NPs at $20 \mu \mathrm{m}$ magnification shows that PMMA-PS exhibit an amorphous nature with a smooth surface. The SEM images show homogenous 
dispersion of $\mathrm{CeO}_{2}$ NPs on the surface of the PMMA-PS thin films. Having obtained an interesting result on exploiting and understanding the physical mechanisms behind tuning the optical parameters of the polymer-inorganic filler nanocomposites, we are motivated to investigate the effect of changing the types of inorganic fillers, as well as their compositional content on tuning optical parameters of different polymer nanocomposites. Such future investigations are predicted to yield organic-inorganic systems of prime importance for the fabrication of state-of-art optoelectronic multifunctional devices. Furthermore, we are planning to introduce transition metal oxides into different polymeric matrices to examine the possibility of inducing strong magnetic properties to fabricate onto magnetic devices.

Our detailed and comprehensive investigations of the optical, morphological, lattice dynamical, and thermal properties of PMMA-PS/ $\mathrm{CeO}_{2} \mathrm{NPs}$ nanocomposite thin films reveal that they could be utilized in manufacturing realistic-scaled smart multifunctional devices.

Author Contributions: Conceptualization, A.A.B.-S., A.A.A., A.M.A., I.A.Q. and I.A.A.; Data curation, A.A.B.-S., A.A.A. and A.M.A.; Formal analysis, A.A.B-S, A.M.A., I.A.A. and A.A.A.; Funding acquisition, A.A.A., A.M.A. and I.A.Q.; Investigation, A.A.B.-S., A.A.A., A.M.A., I.A.Q. and I.A.A.; Methodology, A.A.B.-S., A.A.A., A.M.A., I.A.Q. and I.A.A.; Project administration, A.A.A. and A.M.A.; Resources, A.A.A., A.M.A. and I.A.Q.; Supervision, A.A.A., A.M.A. and I.A.Q.; Validation, A.A.A., A.M.A. and I.A.Q.; Visualization, A.A.B.-S., A.A.A., A.M.A., I.A.Q. and I.A.A.; Writingoriginal draft, A.A.B.-S., A.A.A., A.M.A., I.A.Q. and I.A.A.; Writing-review \& editing, A.A.B.-S., A.A.A., A.M.A., I.A.Q. and I.A.A. All authors have read and agreed to the published version of the manuscript.

Funding: This research received no external funding.

Institutional Review Board Statement: Not applicable.

Informed Consent Statement: Not applicable.

Data Availability Statement: Data availability upon request.

Acknowledgments: The authors would like to thank Jordan University of Science and Technology in Jordan for the support provided by the Deanship of Scientific Research on project number 20180246. The authors would like to thank M-Ali Al-Akhras for his help in using the facilities of the Center of Nanotechnology and the Laboratory of Biomedical Physics.

Conflicts of Interest: The authors declare no conflict of interest.

\section{References}

1. Al-Asbahi, B.A. Influence of $\mathrm{SiO}_{2} / \mathrm{TiO}_{2}$ nanocomposite on the optoelectronic properties of PFO/MEH-PPV-based OLED devices. Polymers 2018, 10, 800. [CrossRef]

2. Wu, S.; Peng, S.; Wang, C.H. Multifunctional Polymer Nanocomposites Reinforced by Aligned Carbon Nanomaterials. Polymers 2018, 10, 542. [CrossRef]

3. Kumar, S.; Sarita; Nehra, M.; Dilbaghi, N.; Tankeshwar, K.; Kim, K.-H. Recent advances and remaining challenges for polymeric nanocomposites in healthcare applications. Prog. Polym. Sci. 2018, 80, 1-38. [CrossRef]

4. Reyes-Acosta, M.A.; Torres-Huerta, A.M.; Domínguez-Crespo, M.A.; Flores-Vela, A.I.; Dorantes-Rosales, H.J.; Andraca-Adame, J.A. Thermal, Mechanical and UV-Shielding Properties of Poly(Methyl Methacrylate)/Cerium Dioxide Hybrid Systems Obtained by Melt Compounding. Polymers 2015, 7, 1638-1659. [CrossRef]

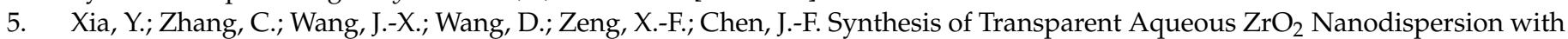
a Controllable Crystalline Phase without Modification for a High-Refractive-Index Nanocomposite Film. Langmuir 2018, 34, 6806-6813. [CrossRef] [PubMed]

6. Wang, W.; Zhang, B.; Jiang, S.; Bai, H.; Zhang, S. Use of $\mathrm{CeO}_{2}$ Nanoparticles to Enhance UV-Shielding of Transparent Regenerated Cellulose Films. Polymers 2019, 11, 458. [CrossRef] [PubMed]

7. Kang, T.; Kim, Y.G.; Kim, D.; Hyeon, T. Inorganic nanoparticles with enzyme-mimetic activities for biomedical applications. Co-ord. Chem. Rev. 2020, 403, 213092. [CrossRef]

8. James, J.; Unni, A.B.; Taleb, K.; Chapel, J.-P.; Kalarikkal, N.; Varghese, S.; Vignaud, G.; Grohens, Y. Surface engineering of polystyrene-cerium oxide nanocomposite thin films for refractive index enhancement. Nano-Struct. Nano-Objects 2019, 17, 34-42. [CrossRef]

9. Lee, L.-H.; Chen, W.-C. High-Refractive-Index Thin Films Prepared from Trialkoxysilane-Capped Poly(methyl methacrylate)Titania Materials. Chem. Mater. 2001, 13, 1137-1142. [CrossRef] 
10. Shambat, G.; Ellis, B.; Majumdar, A.; Petykiewicz, J.; Mayer, M.; Sarmiento, T.; Harris, J.; Haller, E.; Vuckovic, J. Ultrafast directly modulated single-mode photonic crystal nanocavity light-emitting diode. Solid State Devices Mater. 2012, 2, 1-6. [CrossRef]

11. Schneiderman, D.K.; Hillmyer, M.A. 50th Anniversary Perspective: There Is a Great Future in Sustainable Polymers. Macromolecules 2017, 50, 3733-3749. [CrossRef]

12. Hong, M.; Chen, E.Y.-X. Chemically recyclable polymers: A circular economy approach to sustainability. Green Chem. 2017, 19, 3692-3706. [CrossRef]

13. Carotenuto, G.; Giannini, C.; Siliqi, D.; Nicolais, L. Nanocomposites Based on Metal and Metal Sulfide Clusters Embedded in Polystyrene. Polymers 2011, 3, 1352-1362. [CrossRef]

14. Girault, P.; Lorrain, N.; Poffo, L.; Guendouz, M.; Lemaitre, J.; Carré, C.; Gadonna, M.; Bosc, D.; Vignaud, G. Integrated polymer micro-ring resonators for optical sensing applications. J. Appl. Phys. 2015, 117, 104504. [CrossRef]

15. Lü, C.; Yang, B. High refractive index organic-inorganic nanocomposites: Design, synthesis and application. J. Mater. Chem. 2009, 19, 2884-2901. [CrossRef]

16. Zhang, Q.; Fang, Z.; Cao, Y.; Du, H.; Wu, H.; Beuerman, R.; Chan-Park, M.B.; Duan, H.; Xu, R. High Refractive Index InorganicOrganic Interpenetrating Polymer Network (IPN) Hydrogel Nanocomposite toward Artificial Cornea Implants. ACS Macro Lett. 2012, 1, 876-881. [CrossRef]

17. Zhang, Q.; Su, K.; Chan-Park, M.B.; Wu, H.; Wang, D.; Xu, R. Development of high refractive ZnS/PVP/PDMAA hydrogel nanocomposites for artificial cornea implants. Acta Biomater. 2014, 10, 1167-1176. [CrossRef] [PubMed]

18. Rogers, H.G.; Gaudiana, R.A.; Hollinsed, W.C.; Kalyanaraman, P.S.; Manello, J.S.; McGowan, C.; Minns, R.A.; Sahatjian, R. Highly amorphous, birefringent, para-linked aromatic polyamides. Macromolecules 1985, 18, 1058-1068. [CrossRef]

19. Yang, C.J.; Jenekhe, S.A. Effects of Structure on Refractive Index of Conjugated Polyimines. Chem. Mater. 1994, 6, 196-203. [CrossRef]

20. Caglar, M.; Ilican, S.; Caglar, Y.; Yakuphanoglu, F. Electrical conductivity and optical properties of ZnO nanostructured thin film. Appl. Surf. Sci. 2009, 255, 4491-4496. [CrossRef]

21. Soni, G.; Srivastava, S.; Soni, P.; Kalotra, P.; Vijay, Y.K. Optical, mechanical and structural properties of $\mathrm{PMMA} / \mathrm{SiO}_{2}$ nanocomposite thin films. Mater. Res. Express 2017, 5, 015302. [CrossRef]

22. Heiba, Z.K.; Mohamed, M.B.; Mostafa, N.Y.; El-Naggar, A. Structural and Optical Properties of Cd $1-\mathrm{x} \mathrm{Mn}^{\mathrm{F}} \mathrm{Fe}_{2} \mathrm{O}_{4} / \mathrm{PMMA}$ Nanocomposites. J. Inorg. Organomet. Polym. Mater. 2019, 30, 1-9.

23. Soni, G.; Gouttam, N.; Soni, P. Optical properties of PMMA/ZnO/SiO 2 composite thin film. Mater. Today Proc. 2020, $30,35-38$. [CrossRef]

24. Kumar, M.; Arun, S.; Upadhyaya, P.; Pugazhenthi, G. Properties of PMMA/clay nanocomposites prepared using various compatibilizers. Int. J. Mech. Mater. Eng. 2015, 10, 205. [CrossRef]

25. Khaled, S.M.; Sui, R.; Charpentier, P.A.; Rizkalla, A.S. Synthesis of $\mathrm{TiO}_{2}-\mathrm{PMMA}$ Nanocomposite: Using Methacrylic Acid as a Coupling Agent. Langmuir 2007, 23, 3988-3995. [CrossRef] [PubMed]

26. Abdel-Kader, M.H.; Mohamed, M.B. Exploring the direct effect of intermediate band semiconductor materials on the structural, thermal and optical properties of PMMA nanocomposite. Appl. Phys. A 2020, 126, 1-11. [CrossRef]

27. Shih, Y.-F.; Kotharangannagari, V.K.; Tsou, T.-C. Development of eco-friendly modified cellulose nanofiber reinforced polystyrene nanocomposites: Thermal, mechanical, and optical properties. J. Polym. Res. 2020, 27, 1-10. [CrossRef]

28. Okamoto, M. Biodegradable polymer/layered silicate nanocomposites: A review. J. Ind. Eng. Chem. 2004, 10, 1156-1181.

29. Kargarzadeh, H.; Huang, J.; Lin, N.; Ahmad, I.; Mariano, M.; Dufresne, A.; Thomas, S.; Gałęski, A. Recent developments in nanocellulose-based biodegradable polymers, thermoplastic polymers, and porous nanocomposites. Prog. Polym. Sci. 2018, 87, 197-227. [CrossRef]

30. Vignaud, G.; Chebil, M.S.; Bal, J.K.; Delorme, N.; Beuvier, T.; Grohens, Y.; Gibaud, A. Densification and Depression in Glass Transition Temperature in Polystyrene Thin Films. Langmuir 2014, 30, 11599-11608. [CrossRef]

31. Unni, A.B.; Vignaud, G.; Chapel, J.-P.; Giermanska, J.; Bal, J.K.; Delorme, N.; Beuvier, T.; Thomas, S.; Grohens, Y.; Gibaud, A. Probing the Density Variation of Confined Polymer Thin Films via Simple Model-Independent Nanoparticle Adsorption. Macromolecules 2017, 50, 1027-1036. [CrossRef]

32. Lin, S.-S.; Huang, J.-L. Effect of thickness on the structural and optical properties of ZnO films by r.f. magnetron sputtering. Surf. Coatings Technol. 2004, 185, 222-227. [CrossRef]

33. Hameed, S.A.; Saadmahdi, Z.; Jasim, A.N.; Taha, A.F.; Habeeb, A.A. Effect of Thickness on Structural and Optical Properties of CdO Thin Films Prepared by Chemical Spray Pyrolysis Method. NeuroQuantology 2020, 18, 20. [CrossRef]

34. Wu, H.; Shen, S.; Li, J.; Chen, X.; Zhang, Z.; Ou-Yang, W. Boosted field emission properties and thickness effect of conductive polymers coated silicon carbide matrices for vacuum electronic devices. Vacuum 2020, 180, 109594. [CrossRef]

35. Menazea, A.; Mostafa, A.M.; Al-Ashkar, E.A. Effect of nanostructured metal oxides $\left(\mathrm{CdO}, \mathrm{Al}_{2} \mathrm{O}_{3}, \mathrm{Cu}_{2} \mathrm{O}\right)$ embedded in PVA via Nd:YAG pulsed laser ablation on their optical and structural properties. J. Mol. Struct. 2020, 1203, 127374. [CrossRef]

36. Cheng, Y.; Lu, C.; Yang, B. A Review on High Refractive Index Nanocomposites for Optical Applications. Recent Pat. Mater. Sci. 2011, 4, 15-27. [CrossRef]

37. Liu, J.-G.; Ueda, M. High refractive index polymers: Fundamental research and practical applications. J. Mater. Chem. 2009, 19, 8907-8919. [CrossRef] 
38. Tao, P.; Li, Y.; Rungta, A.; Viswanath, A.; Gao, J.; Benicewicz, B.C.; Siegel, R.W.; Schadler, L.S. TiO 2 nanocomposites with high refractive index and transparency. J. Mater. Chem. 2011, 21, 18623-18629. [CrossRef]

39. İncel, A.; Güner, T.; Parlak, O.; Demir, M.M. Null extinction of ceria@ silica hybrid particles: Transparent polystyrene composites. ACS Appl. Mater. Interfaces 2015, 7, 27539-27546. [CrossRef]

40. Nadeem, M.; Khan, R.; Afridi, K.; Nadhman, A.; Ullah, S.; Faisal, S.; Mabood, Z.U.; Hano, C.; Abbasi, B.H. Green Synthesis of Cerium Oxide Nanoparticles (CeO2 NPs) and Their Antimicrobial Applications: A Review. Int. J. Nanomed. 2020, 15, 5951-5961. [CrossRef] [PubMed]

41. Das, S.; Dowding, J.M.; Klump, K.E.; McGinnis, J.F.; Self, W.; Seal, S. Cerium oxide nanoparticles: Applications and prospects in nanomedicine. Nanomedicine 2013, 8, 1483-1508. [CrossRef] [PubMed]

42. Liying, H.; Yumin, S.; Lanhong, J.; Shikao, S. Recent advances of cerium oxide nanoparticles in synthesis, luminescence and biomedical studies: A review. J. Rare Earths 2015, 33, 791-799.

43. Chiu, F.-C.; Lai, C.-M. Optical and electrical characterizations of cerium oxide thin films. J. Phys. D Appl. Phys. 2010, $43,075104$. [CrossRef]

44. Vigneselvan, S.; Manikandan, V.; Petrila, I.; Vanitha, A.; Chandrasekaran, J. Effect of copper substitution on structural, optical and humidity-sensing characteristics of cerium oxide nanoparticles. J. Phys. Chem. Solids 2020, 136, 109173. [CrossRef]

45. Albery, W.B. Acceleration in other axes affects $+\mathrm{Gz}$ tolerance: Dynamic centrifuge simulation of agile flight. Aviat. Space Environ. Med. 2004, 75, 1-6. [PubMed]

46. Viezbicke, B.D.; Patel, S.; Davis, B.E.; Birnie, D.P. Evaluation of the Tauc method for optical absorption edge determination: ZnO thin films as a model system (Phys. Status Solidi B 8/2015). Phys. Status Solidi B 2015, 252, 1700-1710. [CrossRef]

47. Ahmad, A.; Alsaad, A.; Al-Bataineh, Q. Optical and structural characterization of dip synthesized Al-B Co-doped ZnO seeded platforms for $\mathrm{ZnO}$ nanostructures. Appl. Phys. A 2017. [CrossRef]

48. Alsaad, A.; Ahmad, A.; Qattan, I.; Al-Bataineh, Q.M.; Albataineh, Z. Structural, Optoelectrical, Linear, and Nonlinear Optical Characterizations of Dip-Synthesized Undoped ZnO and Group III Elements (B, Al, Ga, and In)-Doped ZnO Thin Films. Crystals 2020, 10, 252. [CrossRef]

49. Al-Bataineh, Q.M.; Alsaad, A.M.; Ahmad, A.A.; Al-Sawalmih, A. Structural, Electronic and Optical Characterization of ZnO Thin Film-Seeded Platforms for ZnO Nanostructures: Sol-Gel Method Versus Ab Initio Calculations. J. Electron. Mater. 2019, 48, 5028-5038. [CrossRef]

50. Al-Bataineh, Q.M.; Alsaad, A.; Ahmad, A.; Telfah, A. A novel optical model of the experimental transmission spectra of nanocomposite PVC-PS hybrid thin films doped with silica nanoparticles. Heliyon 2020, 6, e04177. [CrossRef]

51. Hassanien, A.S.; Sharma, I. Optical properties of quaternary a-Ge15-x Sbx Se50 Te35 thermally evaporated thin-films: Refractive index dispersion and single oscillator parameters. Optik 2020, 200, 163415. [CrossRef]

52. Aziz, S.B.; Abdullah, O.G.; Hussein, A.M.; Ahmed, H.M. From Insulating PMMA Polymer to Conjugated Double Bond Behavior: Green Chemistry as a Novel Approach to Fabricate Small Band Gap Polymers. Polymers 2017, 9, 626. [CrossRef] [PubMed]

53. Hussen, S.A. Structural and optical characterization of pure and $\mathrm{SnZrO}_{3}$ doped PS based polymer nanocomposite. Mater. Res. Express 2020, 7. [CrossRef]

54. Oriaku, C.; Osuwa, J.; Njoku, C. Single oscillator parameters and optical energies of laser irradiated Cu doped cds thin films. Non-Oxide Glasses 2011, 3, 25-30.

55. Yakuphanoglu, F.; Cukurovali, A.; Yilmaz, I. Single-oscillator model and determination of optical constants of some optical thin film materials. Phys. B Condens. Matter 2004, 353, 210-216. [CrossRef]

56. Hassanien, A.; Akl, A.A. Influence of composition on optical and dispersion parameters of thermally evaporated non-crystalline Cd50S50-xSex thin films. J. Alloys Compd. 2015, 648, 280-290. [CrossRef]

57. Güneri, E.; Kariper, A. Optical properties of amorphous CuS thin films deposited chemically at different pH values. J. Alloys Compd. 2012, 516, 20-26. [CrossRef]

58. Wemple, S.H.; DiDomenico, M. Optical Dispersion and the Structure of Solids. Phys. Rev. Lett. 1969, 23, 1156-1160. [CrossRef]

59. Badran, H.A.; Al-Ahmad, A.Y.; Hassan, Q.M.A.; Emshary, C.A. Determination of optical constants and nonlinear optical coefficients of Violet 1-doped polyvinyl alcohol thin film. Pramana 2015, 86, 135-145. [CrossRef]

60. Bakr, N.A.; Jandow, N.N.; Habubi, N.F. Optical and Dispersion Parameters of ZnS Thin Films Prepared by Flash Evaporation Method. Int. Lett. Chem. Phys. Astron. 2014, 39, 52-63. [CrossRef]

61. Badran, H.A. Study on Optical Constants and Refractive Index Dispersion of Neutral red Doped Polymer Film. Am. J. Appl. Sci. 2012, 9, 250-253. [CrossRef]

62. Okutan, M.; San, S.E.; Köysal, O.; Yakuphanoglu, F. Investigation of refractive index dispersion and electrical properties in carbon nano-balls' doped nematic liquid crystals. Phys. B Condens. Matter 2005, 362, 180-186. [CrossRef] 